\title{
Desempenho Silvicultural em Sistema Silvipastoril do Clone H13 de Eucalyptus urograndis em Diferentes Densidades aos 12 Anos
}

\section{Silvicultural Performance on Silvopastoral System of Eucalyptus urograndis Clone H13 at Different Densities after 12 Years of Planting}

\author{
Yuri Saiter Ribeiro*a; Damaris Elias Vera ${ }^{\text {b }}$; Roberto Giolo de Almeidac; Valdemir Antônio Laurac \\ anniversidade Anhanguera-Uniderp. MS, Brasil. \\ ${ }^{b}$ Universidade Estadual de Mato Grosso do Sul. Engenheira Florestal. MS, Brasil. \\ ${ }^{\mathrm{c}}$ Embrapa Gado de Corte. MS, Brasil. \\ *E-mail: agro.yurisaiter@gmail.com
}

\begin{abstract}
Resumo
Neste experimento objetivou-se avaliar o desempenho do clone $\mathrm{H} 13$ de Eucalyptus urograndis (Eucalyptus urophylla $\mathrm{x}$ Eucalyptus grandis) aos 12 anos, em diferentes densidades de plantio em área de pastagens degradadas no Cerrado em Mato Grosso do Sul. Os arranjos populacionais estabelecidos, foram para sistemas de integração pecuária e floresta (IPF, silvipastoris), para uso múltiplo da madeira, como: madeira serrada, construção civil, laminação e postes. O experimento foi realizado em Ribas do Rio Pardo, Mato Grosso do Sul. As árvores foram implantadas em uma roda de competição de Nelder e, em função do desenho experimental, os arranjos populacionais permitiriam avaliar densidades entre 180 e 1.332 plantas $\mathrm{ha}^{-1}$. Entretanto, considerando que o foco deste trabalho foi o sistema silvipastoril, efetuou-se a análise dendrológica nas densidades entre 180 e 584 plantas ha ${ }^{-1}$ [diâmetro a altura do peito (DAP, cm) e altura das plantas, em m] e calculou-se o volume de madeira $\left(\mathrm{m}^{3}\right)$ produzido por árvore e por hectare). Pode-se concluir que para as variáveis altura, diâmetro a altura do peito (DAP) e produção de madeira serrada, a densidade espacial influenciou diretamente nos resultados obtidos, sendo recomendado para sistemas silvipastoris, nessa região do Estado do Mato Grosso do Sul, o plantio entre 180 e 324 plantas ha $^{-1}$.
\end{abstract}

Palavras-chave: Sustentabilidade. Cerrado. Arranjos Populacionais. ILPF.

\begin{abstract}
In this experiment we aimed to evaluate the performance of Eucalyptus urograndis clone H13 (Eucalyptus urophylla $x$ Eucalyptus grandis) after 12 years of planting, in different planting densities in Cerrado pasture areas in Mato Grosso do Sul State (Brazil). The selected population arrangements were for systems of livestock and forest integration, for multiple use of wood, such as: sawn wood, timber, lamination, poles. The trees were implanted in a Nelder competition wheel and, due to the experimental design, the population arrangements would allow evaluate, in experimental area, densities between 180 and 1,332 plants ha ${ }^{-1}$. However, considering that the focus of this work was the livestock and forest integration system (silvopastoral systems), a dendrological analysis was carried out in densities between 180 and 584 plants ha ${ }^{-1}$ (diameter at breast height $(\mathrm{DBH}, \mathrm{cm})$ and height of the plants, in $\mathrm{m})$ and the volume of wood $\left(\mathrm{m}^{3}\right)$ per tree and per hectare was calculated. It can be concluded that for the variables height, diameter at breast height and production of sawn wood, the spatial density directly influenced the results obtained, being recommended for silvopastoral systems, in this region of the State of Mato Grosso do Sul (Brazil), planting between 180 and 324 plants ha'.
\end{abstract}

Keywords: Sustainability. Cerrado. Population Arrangements. ICLF.

\section{Introdução}

O cultivo de eucalipto tem presença de destaque no mercado brasileiro de florestas plantadas e, nos últimos 30 anos, teve um grande impulso graças a uma rede experimental instalada por órgãos públicos e empresas particulares do setor florestal (ANDRADE et al., 2014). Segundo os dados do Sistema Nacional de Informações Florestais (SNIF), a indústria brasileira de base florestal se tornou a mais expressiva da América do Sul, sendo de aproximadamente 7,4 milhões de hectares de florestas plantadas. O estado de Mato Grosso do Sul é o segundo estado em área plantada de eucalipto no Brasil com cerca de 1,3 milhões de ha ${ }^{-1}$, ficando atrás somente do estado de Minas Gerais, que tem aproximadamente 1,84 milhão de ha-1 (SNIF, 2020).

No âmbito nacional, da área total de florestas plantadas,
$31,3 \%$ é destinada para a produção de celulose e papel, $28,2 \%$ para outras finalidades, $25,2 \%$ para carvão vegetal, $12,9 \%$ para lenha e $2,4 \%$ para outros produtos, como casca, folhas e resinas. Estima-se que 76,2\% dessa madeira originaram-se de espécies de Eucalyptus, 20,1\% de espécies de Pinus e 3,7\% originaram-se de outras espécies (IBGE-PEVS, 2018).

Os vários clones de eucaliptos foram desenvolvidos para distintas finalidades a fim de aumentar a produtividade, otimizar as características de madeira e auxiliar na recuperação de áreas degradadas, principalmente quando implantados em sistemas de integração (ANDRADE et al., 2014). Estes sistemas, quando aliados a práticas conservacionistas, demonstraram possuir os pilares da sustentabilidade, e são alternativas bastante econômicas e sustentáveis (TRECENTI, 2014).

Como o estado do Mato Grosso do Sul possui o quarto maior rebanho bovino do Brasil, com aproximadamente 21,5 
milhões de animais (IBGE, 2017), e o desafio principal da cadeia produtiva da carne no estado é o desenvolvimento sustentável e, os sistemas de integração como o Lavoura, Pecuária e Floresta (ILPF) têm-se mostrado eficientes, pois as pastagens nos cerrados, além de possuir extensas áreas degradadas, estão sob uma condição climática que determina estresse térmico/calórico para os animais na maior parte do ano (PORFÍRIO-DA-SILVA, 2015).

No sistema ILPF, as árvores são utilizadas para plantios florestais em associação com cultivos agrícolas e/ou com animais, em uma mesma área, de maneira simultânea ou em uma sequência temporal (FRANCO et al., 2003). Os benefícios que o componente florestal exerce dentro desse sistema são inúmeros, entre eles estão a melhora do uso e conservação do solo, recuperação de áreas degradadas, ciclagem de nutrientes, fluxo de energia ou até mesmo o conforto térmico animal. Além disso, auxiliam na mitigação da emissão de gases de efeito estufa (GEEs), onde o componente florestal atua como agente sequestrador de carbono produzido durante o processo produtivo, resultando em uma opção sustentável (FERREIRA et al., 2012).

Entretanto, ainda são poucos os estudos que avaliam o desenvolvimento de uma determinada espécie arbórea, em um sistema de integração, desde o plantio com as técnicas empregadas nesse sistema, passando por avaliações de desempenho ao longo de todo o ciclo, chegando até a colheita, principalmente quando essa madeira é destinada para usos mais refinados, que demandam mais tempo de crescimento.

Considerando as premissas acima expostas, o objetivo neste trabalho foi avaliar o desempenho do clone de eucalipto H13 (Eucalyptus urograndis), aos 12 anos, em diferentes densidades de plantio, em uma pastagem na Região Leste Mato Grosso do Sul (no Cerrado).

\section{Desenvolvimento}

\subsection{Local e caracterização}

A área experimental encontra-se na Fazenda Nova Brilhante da empresa Ramires Reflorestamentos, em Ribas do Rio Pardo (Rod. BR 262, km 281), coordenadas geográficas $20^{\circ} 31^{\prime} 45,63$ ' S e 5409'16,83' O e altitude média de $369 \mathrm{~m}$, no Estado de Mato Grosso do Sul. O clima é classificado como tropical úmido Aw, segundo a classificação de Köppen, com estação chuvosa, no verão, e seca, no inverno. A precipitação pluvial média anual situa-se em torno de $1.500 \mathrm{~mm}$, sendo os meses de menor precipitação, junho, julho e agosto. A temperatura média anual oscila entre $19^{\circ}$ e $25^{\circ} \mathrm{C}$.

$\mathrm{O}$ solo no local foi caracterizado como Neossolo Quartzarênico, com teores de areia, silte e argila de 90\%, $3 \%$ e $7 \%$, respectivamente. Os valores para a caracterização inicial da fertilidade do solo são apresentados a seguir, respectivamente para as profundidades de $0-20 \mathrm{~cm}$ e 20 $40 \mathrm{~cm}$ : MO (11 e $\left.8 \mathrm{mg} \mathrm{dm}^{-3}\right), \mathrm{pH}(4,0$ e 4,1), P (8 e $3 \mathrm{mg}$ $\left.\mathrm{dm}^{-3}\right) ; \mathrm{K}^{+}\left(0,2\right.$ e $\left.0,1 \mathrm{mmol}_{\mathrm{c}} \mathrm{dm}^{-3}\right) ; \mathrm{Ca}^{2+}\left(1\right.$ e $\left.0 \mathrm{mmol}_{\mathrm{c}} \mathrm{dm}^{-3}\right)$, $\mathrm{Mg}^{2+}\left(1\right.$ e $\left.0 \mathrm{mmol}_{\mathrm{c}} \mathrm{dm}^{-3}\right), \mathrm{H}^{+}+\mathrm{Al}^{3+}\left(28\right.$ e $\left.23 \mathrm{mmol}_{\mathrm{c}} \mathrm{dm}^{-3}\right), \mathrm{Al}^{3+}$ $\left(9\right.$ e $\left.6 \mathrm{mmol}_{\mathrm{c}} \mathrm{dm}^{-3}\right), \mathrm{SB}\left(19\right.$ e $\left.9 \mathrm{mmol}_{\mathrm{c}} \mathrm{dm}^{-3}\right), \mathrm{CTC}(47$ e 32 $\mathrm{mmol}_{\mathrm{c}} \mathrm{dm}^{-3}$ ), V\% (40 e $28 \%$ ), m\% (32 e $42 \%$ ).

A área foi ocupada durante mais de 20 anos por Urochloa decumbens (Stapf) R.D. Webster cv. Basilisk. Para o plantio do eucalipto, o solo foi preparado conforme a rotina utilizada nos plantios comerciais da propriedade: dessecação da gramínea com glifosato (dose conforme massa vegetal) e, após 15 dias, subsolagem a $60 \mathrm{~cm}$ com abertura de sulcos. Na primeira quinzena de maio de 2008 foi realizado o plantio das árvores com mudas comerciais produzidas na Ramires Reflorestamento.

No momento da implantação, cada muda recebeu $0,25 \mathrm{~kg}$ de adubo na fórmula NPK 06-30-06 e 0,03 kg de FTE BR 12, posicionado em duas covetas laterais por muda. Esta adubação foi repetida seis meses após o plantio.

\subsection{Metodologia}

\subsubsection{Desenho experimental}

As árvores foram implantadas em uma roda de competição, segundo o modelo proposto por Nelder (1962), com o clone (híbrido) comercial de eucalipto $\mathrm{H} 13$ (E. urograndis = Eucalyptus urophylla $\mathrm{x}$ E. grandis). O delineamento utilizado foi inteiramente ao acaso (DIC) apresentando como única fonte de variação a densidade de plantio. $\mathrm{O}$ experimento foi avaliado após 12 anos, ou seja, tempo considerado ideal para o corte de madeira com maior valor agregado, destinada em sua maioria, para a serraria.

\subsubsection{Descrição da Roda de Nelder}

A roda de Nelder foi formada por 22 círculos concêntricos (arcos), com raios variando entre $18,48 \mathrm{~m}$ e $67,51 \mathrm{~m}$, com uma taxa de redução de $11 \%$ na densidade (árvores $\mathrm{ha}^{-1}$ ) e $6 \%$ de aumento na distância entre cada novo arco/círculo. Os círculos concêntricos foram identificados por letras, sendo a letra ' $A$ ' para o círculo mais interno até a letra ' $V$ ' para o círculo mais externo. Os dois círculos mais internos (A e B) e os dois círculos mais externos ( $\mathrm{U}$ e $\mathrm{V}$ ) foram considerados, respectivamente, como bordaduras internas e externas.

O ângulo entre os raios da roda foi de $15^{\circ}$, resultando em 24 raios (numerados de 1 a 24) e, consequentemente 24 árvores plantadas em cada um dos círculos. O raio número 1 foi locado no sentido Norte. Este arranjo permitiria a avaliação (na área útil, do arco $\mathrm{C}$ ao arco $\mathrm{T}$ ) das seguintes densidades de árvores: 1.332, 1.184, 1.052, 935, 832, 739, 657, 584, 519, 461, 410, 365, 324, 288, 256, 225, 202 e 180 plantas $\mathrm{ha}^{-1}$. Entretanto, considerando que o foco deste trabalho foi o sistema de integração pecuária e floresta (silvipastoril), efetuou-se a análise dendrológica nas densidades entre 180 a 584 plantas $\mathrm{ha}^{-1}$, porque densidades superiores inviabilizam o crescimento da pastagem, pelo sombreamento excessivo.

\subsubsection{Variáveis avaliadas}

Ao final do ciclo, de 12 anos, foram avaliadas as seguintes 
características:

- Altura - altura total das árvores $(\mathrm{H})$, obtida com um clinômetro e hipsômetro Haglof HEC-2 (expressa em m);

- Diâmetro a altura do peito (DAP) - foi obtida a circunferência a altura do peito (CAP) a 1,3 m acima do nível do solo com uma fita métrica, fornecendo o valor direto da característica, que foi dividida por $\pi(3,14159 \ldots)$ para obtenção do valor do diâmetro a altura do peito (DAP, expresso $\mathrm{em} \mathrm{cm}$ );

- Volume do fuste (com casca) por árvore - a partir dos valores de $\mathrm{H}$ e DAP, foi obtido o volume de madeira de cada árvore empregando a fórmula proposta por Schumacher e Hall (1933), conforme Campanha et al. (2017), onde V = $\mathrm{DAP}^{1,8801 * \mathrm{H}^{0,989}}$, expresso em $\mathrm{m}^{3}$;

- Volume para serraria por árvore - foi obtido o volume, para cada árvore, empregando a fórmula proposta por Pereira et al. (2018): (DAP $\left.{ }^{1,8233 *} \mathrm{H}^{1,1608}\right) *\left(1-0,36 * \mathrm{Dms}^{3,1133} / \mathrm{DAP}^{2,8833}\right)$, expresso $\mathrm{em}^{3}$ ) onde Dms $=$ Diâmetro mínimo para serraria, estabelecido como $18 \mathrm{~cm}$ para esses cálculos;

- Volume de madeira serrada por árvore - foi obtido dividindo-se o volume para serraria por árvore por quatro, empregando a fórmula proposta por Schumacher e Hall (1933), conforme Campanha et al. (2017).

- Volume do fuste (com casca) e volume para serraria por hectare foram obtidos multiplicando os valores individuais das variáveis pelas respectivas densidades de plantio;

\subsubsection{Análise estatística}

Os dados foram submetidos à análise de variância e as médias agrupadas pelo teste de Scott-Knott a 95\% de probabilidade, por meio do programa R 3.5.1.

\subsubsection{Resultados e Discussão}

Para o diâmetro a altura do peito (DAP) (Figura 1), pôde-se observar que em sistemas em que há um menor adensamento populacional, as árvores apresentam maior DAP. Foram formados três grupos (ou classes), maior DAP para as menores densidades (180, 202 e 225 árvores ha $\left.{ }^{-1}\right)$; DAP intermediário para as densidades intermediárias (256, 288, 365 e 410 árvores ha ${ }^{-1}$ ) e, o menor DAP para as maiores densidades (461, 519 e 584 árvores ha $\left.{ }^{-1}\right)$. O DAP na densidade 324 árvores ha ${ }^{-1}$ agrupou-se aos menores valores.

Figura 1 - Diâmetro a altura do peito (DAP), em $\mathrm{cm}$, de plantas de eucalipto $\mathrm{H} 13$ aos 12 anos, nas diversas densidades de plantio, no município de Ribas do Rio Pardo, MS. Barras com cores diferentes diferem estatisticamente entre si $(5 \%)$

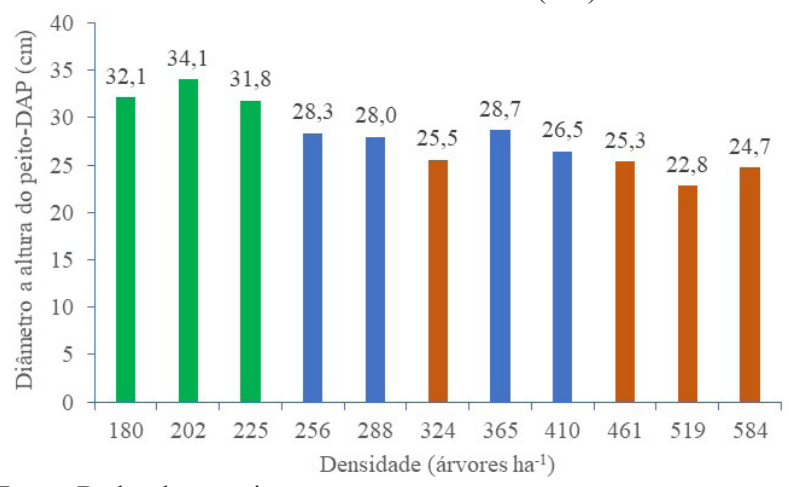

Fonte: Dados da pesquisa.

Os resultados encontrados nesse trabalho corroboram os estudos realizados por Reiner et al. (2011), que afirmaram que DAP é altamente relacionado ao espaçamento, e que há uma maior disputa por nutrientes, água e luz em espaçamentos mais densos, o que acaba afetando o crescimento em diâmetro das plantas. Esse comportamento das plantas foi observado também por Silva et al. (2015), relatando que o bom desempenho em maiores espaçamentos se dá por uma menor competição entre as plantas.

Observa-se na Figura 2, que nas densidades de plantio entre 365 e 584 plantas $^{-1} \mathrm{f}^{-1}$ foram obtidas as maiores alturas, o que pode ser explicado, em parte, por Taiz e Zeiger (2004), que relataram que o maior crescimento em altura por plantas que compõem o centro do experimento em rodas de competição é resultado da maior competição por luz solar, fundamental para o desenvolvimento das plantas. O que também foi confirmado por Hsing et al. (2016) e Torres et al. (2016), que relataram que em espaçamentos menores o crescimento em altura das plantas é maior.

Figura 2 - Altura das plantas, em metros, de eucalipto H13 aos 12 anos, nas diversas densidades de plantio, no município de Ribas do Rio Pardo, MS. Barras com cores diferentes diferem estatisticamente entre si $(5 \%)$

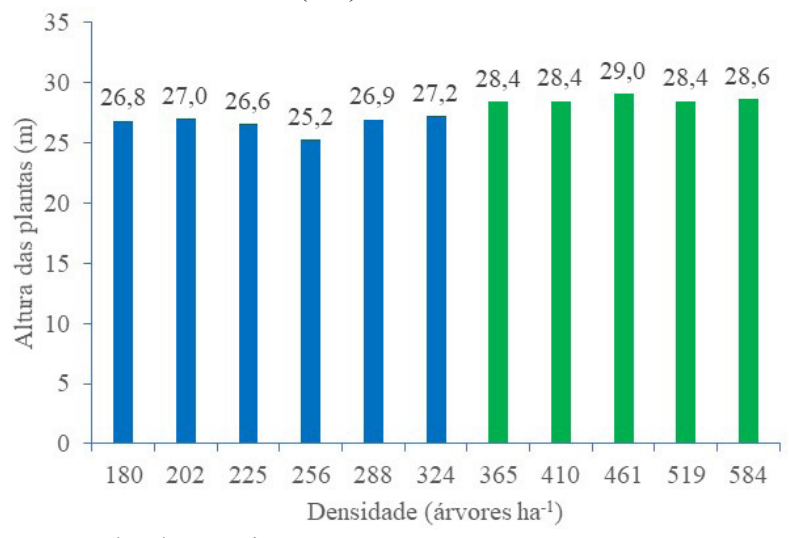

Fonte: Dados da pesquisa.

No entanto, Magalhães (2007) menciona que a altura nas plantas de eucalipto é influenciada somente pelo seu potencial genético, não sendo determinada por práticas silviculturais e espaçamento. Contudo, Bernardo (1995) e Ferreira et al. (2017) ratificam que o espaçamento entre plantas exerce grande influência na altura, sendo que arranjos espaciais mais adensados proporcionam maiores alturas, em função, principalmente, da competição por luminosidade e, podem levar a produção de árvores com menores DAP.

Diversos são os fatores que podem influenciar no crescimento de espécies vegetais arbóreas e de acordo com Silva et al. (2011), as análises de crescimento são consideradas excelentes indicativos quando se tem como objetivo avaliar a produção diretamente influenciada por fatores ambientais, genéticos e agronômicos.

Gomes et al. (1977), por exemplo, relatam que o crescimento em altura é o fator determinante para sobrevivência de árvores em competição, sendo assim, um dos parâmetros mais corretos para apontar se a espécie está ou não adaptada ao local de plantio. Assim, os resultados desse 
trabalho, para altura, coadunam com a maioria dos dados de literatura.

Avaliando a influência da densidade populacional no volume individual, com casca (Figura 3) e de madeira destinada para serraria (Figura 4), pôde-se observar a formação de dois grupos (ou classes), um grupo onde em menores densidades $\left(180,202\right.$ e 225 plantas ha $\left.{ }^{-1}\right)$, ou seja, em sistemas em que há menos competição, o desempenho individual é maior. No outro grupo, onde tiveram as maiores densidades (256, 288, 324, 410, 461, 519 e 584 árvores ha ${ }^{-1}$ ) o desempenho individual foi menor.

Figura 3 - Volume de madeira com casca por árvore, em $\mathrm{m}^{3}$, de plantas de eucalipto $\mathrm{H} 13$ aos 12 anos, nas diversas densidades de plantio, no município de Ribas do Rio Pardo, MS. Barras com cores diferentes diferem estatisticamente entre si $(5 \%)$

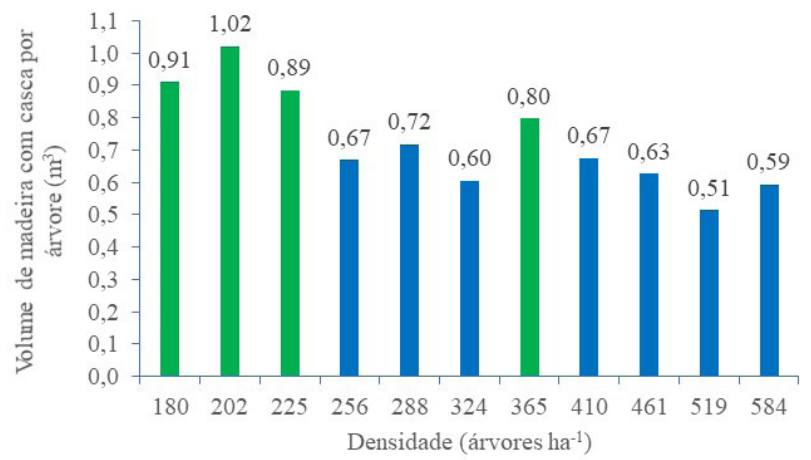

Fonte: Dados da pesquisa.

Constata-se que o volume de madeira por árvore, em sistemas com plantio menos adensados é maior, o que é explicado por Sereghetti et al. (2015), que afirmam que a concorrência ocorre não só por espaço para crescimento radicular, mas também por competição por nutrientes, água e luz solar. Oliveira et al. (2010) afirmam que essa variável foi altamente influenciada pelos espaçamentos utilizados em seu experimento, e que os maiores valores observados foram em arranjos em que havia menor número de plantas por hectare.

Figura 4 - Volume de madeira para serraria por árvore, em $\mathrm{m}^{3}$, de plantas de eucalipto $\mathrm{H} 13$ aos 12 anos, nas diversas densidades de plantio, no município de Ribas do Rio Pardo, MS. Barras com cores diferentes diferem estatisticamente entre si $(5 \%)$

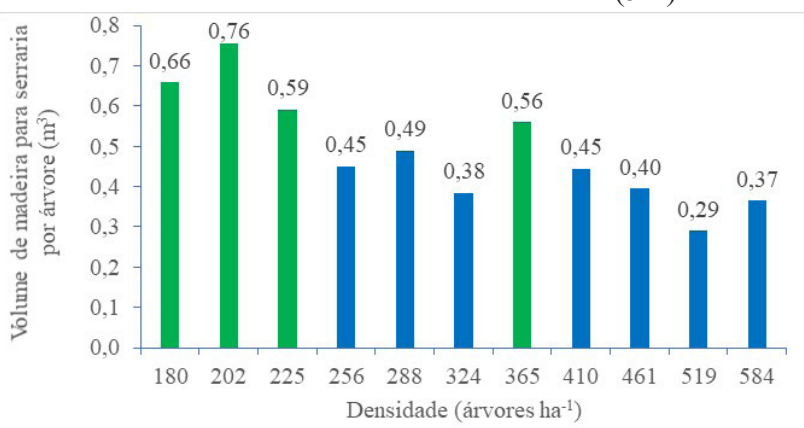

Fonte: Dados da pesquisa.

Figura 5, pode-se notar, quando é avaliada a produção de madeira com casca por hectare, um comportamento diferente dos observados para árvores individualmente, ou seja, em arranjos mais densos, onde há um menor volume de madeira por árvore (Figuras 3 e 4), essa redução é compensada pelo maior número de árvores presentes no arranjo populacional.

Os resultados foram agrupados em três classes, a primeira com o menor volume de madeira por ha (média de 190,67 $\mathrm{m}^{3}$ ), nas menores densidades (180 a 324 plantas ha-1), a segunda, com volume intermediário de madeira por ha (média de 281 $\mathrm{m}^{3}$ ), nas densidades entre 365 e 519 plantas ha-1) e, isolada a densidade de 584 árvores ha ${ }^{-1}$, com o maior volume de madeira $\left(347 \mathrm{~m}^{3}\right)$.

Pode-se concluir que em sistemas em que há menos competição, o desempenho individual é maior, entretanto, não é suficiente para compensar o maior número de árvores em sistemas mais densos.

Figura 5 - Volume do fuste, em $\mathrm{m}^{3}$, por hectare de plantas de eucalipto $\mathrm{H} 13$ aos 12 anos, nas diversas densidades de plantio, no município de Ribas do Rio Pardo, MS. Barras com cores diferentes diferem estatisticamente entre si $(5 \%)$

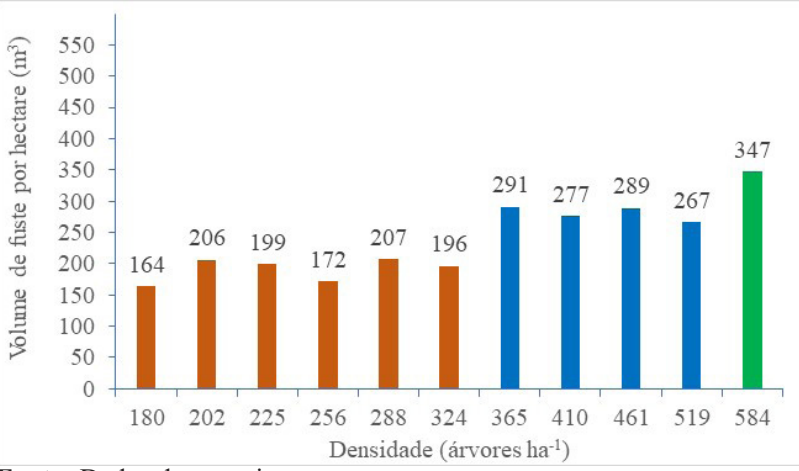

Fonte: Dados da pesquisa.

Muller et al. (2005) reiteram que o espaçamento de plantio influencia o volume de madeira por hectare, por conta de que os plantios com espaçamentos mais adensados atingem a capacidade de sítio primeiro. De acordo com Prodan et al. (1997) a capacidade de sítio é definida pela tendência que uma determinada área tem para o crescimento e desenvolvimento de uma espécie em função de suas condições ambientais (edáficas, climáticas e bióticas) existentes.

Assim como para o volume do fuste por hectare (Figura 5), o volume de madeira destinada a serraria por hectare (Figura 6), mesmo em plantios mais adensados, onde há uma maior competição entre as plantas, há uma tendência de que o menor volume de madeira por árvore, seja compensado pelo maior número de plantas. Os resultados foram agrupados em duas classes, uma com o menor volume de madeira destinada a serraria por hectare (média de $131 \mathrm{~m}^{3}$ ), nas menores densidades (180 a 324 plantas ha ${ }^{-1}$ ), e a outra classe com volume maior (média de 195,5 $\mathrm{m}^{3}$ ), nas densidades de 365 , 410, 461 e 584 plantas ha-1.

Schneider (1993), afirma que em menores espaçamentos há uma produção menor em diâmetro, porém, um maior volume de madeira por área. Enquanto que em maiores espaçamentos, acontece o inverso, um maior volume de madeira por árvore, por conta dos maiores diâmetros. O diâmetro é uma variável fundamental para o volume de madeira destinada a serraria, 
pois há um diâmetro mínimo para que a madeira tenha esse destino. Nesse trabalho foi considerado o DAP de $18 \mathrm{~cm}$ (BRANCALION, 2016).

Figura 6 - Volume de madeira, em $\mathrm{m}^{3}$, destinada a serraria por hectare, de plantas de eucalipto $\mathrm{H} 13$ aos 12 anos, nas diversas densidades de plantio, no município de Ribas do Rio Pardo, MS. Barras com cores diferentes diferem estatisticamente entre si $(5 \%)$

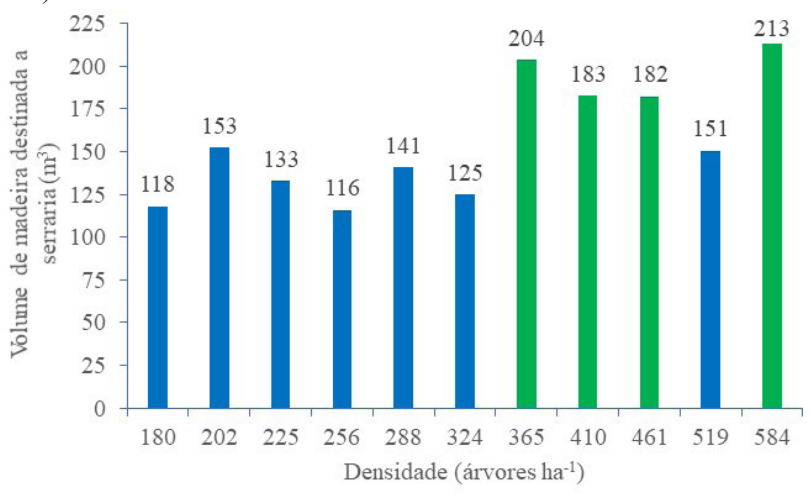

Fonte: Dados da pesquisa.

Ao avaliar a influência dos espaçamentos em povoamentos florestais, Oliveira et al. (2010) concluíram que o tempo é um fator determinante para minimizar a diferença em volume de madeira por hectare de plantios mais adensados para os menos adensados. Acredita-se que o tempo de crescimento das árvores nesse experimento (12 anos) foi suficiente para que houvesse esse efeito.

\section{Conclusão}

Com base nos resultados obtidos, pôde-se concluir que, A densidade de plantio influencia a altura, o Diâmetro a Altura do Peito (DAP) e consequentemente a produção de madeira por árvore e por hectare;

\section{Referências}

ANDRADE, G.C. et al. Desempenho em clones de Eucalyptus no oeste do estado do Paraná. In: ENCONTRO BRASILEIRO DE SILVICULTURA, 3, 2014, Colombo. Anais... Colombo: Embrapa Floresta, 2014. p.173-175.

BATISTA, E.L. da S. et al. Cenários para intensificação da bovinocultura de corte brasileira. Belo Horizonte: IGC/UFMG, 2020.

BALBINO, L.C.; BARCELlOS, A.O.; STONE, L.F. (Ed.). Marco referencial: integração lavoura-pecuária-floresta. Brasília: Embrapa, 2011.

BERNARDO, A.L. Crescimento e eficiência nutricional de Eucalyptus spp. sob diferentes espaçamentos na região de cerrado de Minas Gerais. Viçosa: Universidade Federal de Viçosa, 1995.

BRANCALION, P.H.S. Colheita de madeira em pequenas propriedades rurais. In: RECURSOS FLORESTAIS EM PROPRIEDADES AGRÍCOLAS, 2016, Piracicaba. Piracicaba: ESALQ, 2016.

CAMPANHA, M.M.; COSTA, T.C.C.; GONTIJO NETO, M.M. Crescimento, estoque de carbono e agregação de valor em árvores de eucalipto em um sistema de Integração Lavoura-Pecuária-
Floresta (ILPF) no cerrado de Minas Gerais. Sete Lagoas: Embrapa Milho e Sorgo, 2017. (Embrapa Milho e Sorgo. Boletim de Pesquisa e Desenvolvimento, 157)

FERREIRA, A.D. et al. Potential of environmental services of eucalyptus on integrated production systems. In: INTERNATIONAL SYMPOSIUM ON GREENHOUSE GASES IN AGRICULTURE, 2016, Campo Grande, MS. Proceedings.... Campo Grande, MS: Embrapa Gado de Corte, 2016.

FERREIRA, A.D. et al. Influência de arranjos espaciais sobre características silviculturais de três clones de eucalipto em sistemas de integração lavoura-pecuária-floresta. Campo Grande: Embrapa Gado de Corte, 2017.

FRANCO, A.A.; RESENDE, A.S.; CAMPELLO, E.F.C. Importância das leguminosas arbóreas na recuperação de áreas degradadas e na sustentabilidade de sistemas agroflorestais. In: SEMINÁRIO SISTEMAS AGROFLORESTAIS E DESENVOLVIMENTO SUSTENTÁVEL, 1, 2003, Campo Grande. Anais... Campo Grande: Embrapa Gado de Corte, 2003.

GOMES, J.M. et al. Competição de espécies e procedências de eucalipto na região de Viçosa, Minas Gerais. Rev. Árvore, v.1, n. 2, p.72-88, 1977.

HSING, T.Y.; PAULA, N.F. de; PAULA, R.C. de. Características dendrométricas, químicas edensidade básica da madeira de híbridos de Eucalyptus grandis X Eucalyptus urophylla. Ciênc. Florestal, v.26, n.1, p.273-283, 2016. doi:10.5902/1980509821119.

IBGE: Instituto Brasileiro de Geografia e Estatística. PEVS Produção da extração vegetal e da silvicultura. 2018. Disponível em: https://biblioteca.ibge.gov.br/visualizacao/periodicos/74/ pevs_2018_v33_informativo.pdf Acesso em: 1 ago. 2020.

IBGE: Instituto Brasileiro de Geografia e Estatística, "Censo Agro 2017 - Resultados preliminares Mato Grosso do Sul”. Disponível em: https://censoagro2017.ibge.gov.br/templates/ censo_agro/resultadosagro/pdf/MS.pdf. Acesso em: 25 fev. 2020.

IPCC - Intergovernmental Panel on Climate Change. 2006 IPCC Guidelines for National Greenhouse Gas Inventories. Japan: IGES, v.4, 2006.

KICHEL, A.N.; MIRANDA, C.H.B. Sistema de integração agricultura \& pecuária. Campo Grande; Embrapa Gado de Corte, 2001.

MAGALHÃES, W.M. Desempenho silvicultural de clones e procedências de Eucalyptus em diferentes espaçamentos na região Nordeste de Minas Gerais. Lavras: Universidade Federal de Lavras, 2007.

MULLER, M.D. et al. Avaliação de um clone de eucalipto estabelecido em diferentes densidades de plantio para produção de biomassa e energia. Biomassa \& Energia, v.2, n.3, p.177-186, 2005.

NELDER, J.A. New kinds of systematic designs for spacing experiments. Biometrics, v.18, n.2, p.283-307, 1962.

OLIVEIRA, T.K. et al. Desempenho silvicultural e produtivo de eucalipto sob diferentes arranjos espaciais em sistema agrossilvipastoril. Pesq. Florestal Bras., n.60, p.1-10, 2010. doi: 10.4336/2009.pfb.60.01

OLIVEIRA, E.B.; PORFIRIO-DA-SILVA, V.; RIBASKI, J. SisILPF: software para simulação do crescimento, produção, metano e manejo do componente florestal em sistemas de integração lavoura-pecuária-floresta. In: ENCONTRO BRASILEIRO DE SILVICULTURA, 4., 2018, Ribeirão Preto. Anais. Brasília, DF: Embrapa; Colombo: Embrapa Florestas, 2018. p.127-133.

PORFÍRIO-DA-SILVA, V. et al. Arborização de pastagens com 
espécies florestais madeireiras: implantação e manejo. Colombo: Embrapa Florestas, 2009.

PRODAN, M. et al. Mensura florestal, San José: IICA, 1997.

REINER, D.A.; SILVEIRA, E.R.; SZABO, M.S. Uso do eucalipto em diferentes espaçamentos como alternativa de renda e suprimento da pequena propriedade na região sudoeste do paraná. Synergismus Scyentifica, v.6, n.1, p.100-107, 2011.

RIBEIRO, M.D.S.B. et al. Avaliação da produção de biomassa do fuste de um clone híbrido de eucalipto sob diferentes espaçamentos. Ciênc. Florestal, v.27, n.1, p.31-51, 2017.

SCHNEIDER, P.R. Introdução ao manejo florestal. Santa Maria: UFSM; CEPEF; FATEC, 1993.

SCHUMACHER, F.X.; HALL, F.S. Logarithmic expression of timber-tree volume. J. Agricultural Res., v.47, n.9, p.719-734, 1933.

SCOTT CONSULTORIA. O caminhar da pecuária brasileira. Disponível $<$ https://www.scotconsultoria.com.br/noticias/ artigos/50006/o-caminhar-da-pecuaria-brasileira.htm. > Acesso em 27 jun. 2020 .

SEREGHETTI, G.C. et al. Efeito do espaçamento no crescimento e na densidade básica da madeira de Eucalyptus urophylla $\mathrm{x}$ Eucalyptus grandis em florestas de ciclo curto. Energia Agricul., v.30, n.3, p.257-262, 2015.
SILVA, A.C. da. et al. Crescimento de figueira sob diferentes condições de cultivo. Pesq. Agropec. Trop., v.41, n.4, p.539-551, 2011.

SILVA, A.R. et al. Cultivo de milho sob influência de renques de paricá em sistema de integração lavoura-pecuária-floresta. Rev. Bras. Agropec. Sustentável, v.5, n.1, p.110-114, 2015.

SNIF. Sistema nacional de informações florestais - Brasília: 2019. Disponível em: <http://snif.florestal.gov.br/pt-br/florestasplantadas/452-painel-interativo-1a $>$ Acesso em: 6 mar. 2020.

TAIZ, L.; ZEIGER, E. Fisiologia vegetal. Porto Alegre: ArtMed, 2004.

TRECENTI, R. Integração lavoura-pecuária-floresta. In: CONGRESSO NORDESTINO DE PRODUÇÃO ANIMAL, 9, 2014, Ilhéus. Anais... Ilhéus: Sociedade Nordestina de Produção Animal e Universidade Federal do Recôncavo Bahiano, 2014, p.358-371.

TSUKAMOTO FILHO, A.A. Fixação de carbono em um sistema agroflorestal com eucalipto na região do Cerrado de Minas Gerais. Viçosa: Universidade Federal de Viçosa, 2003.

TORRES, C.M.M.E. et al. Estimativas da produção e propriedades da madeira de eucalipto em Sistemas Agroflorestais. Scie. Forestalis, v.44, n.109, p.137-148, 2016. 